\section{RESISTÊNCIAS DE CORPOS NEGROS E (IN)DÓCEIS DE PESSOAS EM SITUAÇÃO DE RUA DA CIDADE DE ALAGOINHAS-BA}

\section{RESISTANCE OF BLACK BODIES AND (IN) DOCILE OF PEOPLE IN STREET SINTUACION OF THE CITY OF ALAGOINHAS-BA}

Ariel Dantas Barbosa ${ }^{1}$

A desigualdade social hoje é algo que assola toda a comunidade, a classe trabalhadora sofre constantemente com as barbáries dos governos, sendo sempre ela a mais atingida em meio ao caos vivido. Essa sociedade trabalhadora sofre com isso a anos, sendo ela também uma sociedade de cor, em especial, preta, que constantemente vem sendo alvo dos fatores resultantes desses processos, aumentando o índice de pobreza.

Identidade racial/étnica parte do pressuposto de uma crença de pertencimento a um grupo racial ou étnico que vem através de uma construção social, cultural e política, que se cruza com a história de vida (socialização/educação) que vem sendo construída e adquirida diante das "prescrições sociais ou étnicas, racistas ou não de uma dada cultura" (OLIVEIRA, 2004, p. 01). Assumir uma identidade negra no Brasil não é tarefa fácil. Os modelos de identidade negra que podemos classificar como "positivos", "bons" e de "sucesso" são poucos e os que existem, não há ampla divulgação. Quando se trata do respeito às diferenças em relação as identidades raciais/étnicas por ora, inexistente (Idem).

A população de rua, por exemplo, é resultado de políticas mal elaboradas que expurgaram de maneira cruel essas pessoas a esta situação, tendo ela, origem na última década do século XX e o início do século XXI, onde o ajuste estrutural os levou para as ruas. Os fatores que os levaram a esse ambiente no Brasil, assim como na Europa foi o processo de industrialização e urbanização. Hoje, esse fenômeno está voltado a fatores "indeterminados", mas que está fortemente ligado à desigualdade e a nossa sociedade capitalista, sendo as ruas palco de cenas corriqueiras em que essas pessoas vivem invisibilizados, não só pelos transeuntes, mas pelo Estado, a invisibilidade dos grandes que não enxergam os menores.

\begin{abstract}
RESUMO
Este Trabalho, visa discutir duas questões centrais, a questão de raça (negro) e a situação social (pessoas em situação de rua) de como isso se mistura na atual conjuntura social, tornando a vida dessas pessoas mais densas e dolorosas. O termo Indocilidade foi a maneira encontrada para tratar dessas pessoas que vivem de maneira (des) igual ao que a comunidade está acostumada, sendo esse um termo tratado na obra de Foucault (1987) como docilidade, também tratado Indocilidade na obra de Santiago (2016), entre outros autores que tratarão das questões. É um trabalho que vem sendo estudado in locus, com pessoas que vivem na rua cotidianamente, estudando preponderantemente as questões de resistências, da estética da existência e de como a arte pode ser uma válvula de escape no processo de reconstrução desses sujeitos que são marginalizados e invisibilizados constantemente, por uma sociedade que historicamente foi e é construída sob o massacre e desigualdade, desta forma trataremos de maneira assertiva como essas pessoas diferente do padrão intitulado normal (Indóceis), sobrevivem na rua e de como a arte pode ser um objeto de "escrita de si" e reconstrução de um eu que existe e resiste à descriminação racial e desigualdade social.
\end{abstract}

Palavras Chave: Pessoas em situação de rua. Racismo. Arte. Existência

\section{ABSTRACT}

His academic work, aims to discuss two main issues, the race issue (black) and the social situation (street people) of how this mixes in the current social context making their lives more dense and painful. The term Indocility was the way of treating those people living in a (un)equal way to what the community is used to, a term treated in the work of Foucault (1987) as docility, also treated Indocility in the work of Santiago (2016), among other authors who will deal with the issues. It is a work that has been studied in loccus, with people living on the street everyday, studying preponderantly the issues of resistance, the aesthetics of existence and how art can be a valve of escape in the process of reconstruction of those who are marginalized and constantly invisibilized by a society that historically was and is built under massacre and inequality, in this way we will treat assertively how these people different from the standard titled normal (Indociles) survive on the street and how art can be an object of "writing of self" and reconstruction of a self that exists and resists racial discrimination and social inequality.

Keywords: Street People. Racism. Art. Existence

Submetido em: 26 de abr. 2019

Aceito em: 04 de nov. 2019

${ }^{1}$ Universidade do Estado da Bahia, Alagoinhas, Bahia - Brasil

*E-mail para correspondência: Arieldanttas@hotmail.com

Rev. ComCiência - dez. 2019, vol. 4, no. 5, p. 47-54 / doi: 10.36112/issn2595-1890.v5i2.p47-54 
A população de rua reflete o movimento de urbanização e distribuição de renda mal planejados do nosso país, que diante disso marcou desigualdades sociais que por sua vez afetou as classes mais pobres, impossibilitando as mínimas garantias. O aumento de populações em extrema pobreza tem como consequência o aumento das populações em situação de rua. Esses grupos são estereotipados como, marginais, bandidos, vagabundos dentre outros rótulos que cercam a vida da população em situação de rua, por serem uma parcela "inativa", e não gerar lucro ao sistema capitalista, sendo quase descartáveis economicamente.

Pensar nessa exclusão tornou-se algo urgente visto que ela, coloca esse sujeito as margens da sociedade causando grandes rupturas de seus vínculos, valores e representações sociais, o que na maioria das vezes, o impede de se posicionar como agente de mudanças ou de pensar sobre isso por tratarse da maneira que é reconhecido e por esta num ambiente em que a relação de forca opera no ceio dela (FOUCAULT, 2004).

$\mathrm{O}$ interesse em pesquisar esses sujeitos, surgiu desde a graduação em Psicologia, quando frequentava o centro espírita. Fomos fazer uma ação social, que seria a entrega de sopa, e vendo aquela situação drástica, fiquei comovido, incomodado. A partir de então, na época, decidi falar no meu trabalho de conclusão de curso sobre essa população. Como imaginado, não foi fácil, o meu medo e a insegurança dos possíveis orientadores em relação àquelas pessoas eram muito maiores que $o$ meu enquanto pesquisador/estudante que iria a campo ter o contato direto com aquelas pessoas que para nós eram estranhas, por isso causavam medo.

Toda essa história serve para podermos analisar desde já a resistência que temos em enxergar essas pessoas como gente, sendo assim ouso a destacar dois motivos que levam essas pessoas a viverem excluídos e a margem da sociedade: o primeiro, a situação que vivem essas pessoas, sujas, com mal cheiro, sob o uso de substancias psicoativas, o outro sua cor. A maioria da população de rua é preta. Das sete pessoas que eu trabalho/pesquiso, as sete são pretas. "O preconceito racial arraigado às relações cotidianas como uma rotina sendo cumprida por todos. A visão depreciativa do negro é uma constante na sociedade" (FIGUEREDO, 2009, p. 48). O racismo nos leva ao julgamento prévio e associação da imagem desses sujeitos à violência e nos submete ao medo, o nojo e por consequência lhes submetemos a exclusão. Inicialmente a percepção e o sentimento de medo vem tão somente porque eles vivem na rua, posteriormente vem a junção de dois fatores, viver na rua e ser negro, é por isso que me debruço aqui para falar de maneira discursiva sobre as questões supracitadas.

Para tanto, esse trabalho se caracteriza como uma pesquisa de base qualitativa etnográfica onde foi possível entrar em contato com essas pessoas de maneira direta, dialogar e acima de tudo, conhecer, observar como se dão os modos de vida e de produção. Para essa pesquisa, foi necessário ir a campo onde foi possível um contato direto, com entrevistas semiestruturadas em que a cada encontro era lançada uma pergunta ao grupo, para esse trabalho a pergunta era "o racismo existe? Vocês também sofrem com isso?" e a partir desse momento, passou-se a discuti sobre estas ques- tões. Para isso foi levado o termo de consentimento livre e esclarecido (TCLE), em que eles assinaram e os que não sabiam escrever botaram suas digitais. Com esses encontros foi possível perceber que há uma forte existência de arte que por sua vez também é invisibilizada em decorrência da sua situação de extrema pobreza. Assim colocamos essa arte como um objeto de resistência de uma população subalternizada, fazendo dessa arte que versa sobre versos, pinturas e artesanato, um símbolo de luta que se dirige para a potência de resistir e criar que também serão mostradas nesse texto. A arte aqui mencionada como nos diz, (AGUIAR, BASTOS 2013, p.11) "Deixa de ser um núcleo relativamente definido e estável - como era, por exemplo, a forma no modernismo para antes constituir essa produção de imagens acerca da arte". Nesse contexto a arte desdobra-se como espaço de debate e desmonte dos discursos de opressão, apresenta-se como dispositivo de luta contra uma população hegemônica centrada no capitalismo, é revelada por meio de, pinturas, música, poesia e textos afirmando sua subjetividade e identidade, como uma forma de resistir (SANTOS, 2016).

Aproveito o ensejo para lembralos que o objetivo do trabalho não é dar voz a essas pessoas, pois configura um termo impróprio visto que, como autor, não me reconheço como população de rua, não podendo assumir essa postura, o que eu faço é visibilizar estratégias como estas com artigos científicos que deem aos leitores um olhar diferente do que estamos acostumados a pensar.

As relações étnicas raciais misturam-se às questões socais de maneira homogênea. $\mathrm{O}$ racismo é um fator permanente na sociedade que interage concomitantemente com a pobreza, e 
isso não é uma questão de intelectualidade mas, um fator histórico de um povo que sofreu a exclusão desde o ventre, e que os grandes resultados são apresentados expostamente nos nossos cotidianos, nas ruas, em baixo de viadutos, em baixo das arvores, comendo do que lhe é ofertado ou do próprio lixo. São vidas sem diretos a educação e saúde. O racismo mistura-se em uma crença de dominação e ódio que são aliançados, tendo como consequência o processo de exclusão que Foucault (2004) chamará de um processo de interdição de um sujeito que é inferior dominado, em que só o dominador tem o direto privilegiado e exclusivo por ter a fala que por conter esse poder causa uma separação e rejeição. $O$ autor nos traz uma síntese clara do que são acometidas essas pessoas. E é a partir dessa breve introdução que iremos começar a discutir, como sobrevivem esses corpos (indóceis) por viver fora de um padrão e sua maneira de (re) existências, sejam na arte como pintura, músicas, textos, artesanatos ou na própria arte de existir.

\section{A (in) docilidade do corpo negro na rua}

Para iniciarmos, o termo indocilidade deriva do termo indócil que é utilizada por Ana Rita Santiago (2010) na sua tese de Doutorado, onde ela trata deste termo em relação aos corpos de mulheres negras, escritoras e periféricas. Desta forma, aproprio-me desse termo para falar de pessoas em situação de rua e negras, utilizando-me também da obra de Focault, Vigiar e punir no capítulo Os Corpos Dóceis.

"Docilidade une ao corpo analisável o corpo manipulável. É dócil um corpo que pode ser submetido, que pode ser utilizado, que pode ser transformado e aperfeiçoado.” (FOU-
CAULT, 1987, p. 02) O autor nos informa que os corpos dóceis obedecem às leis regentes, que nesse caso é a do trabalho, o corpo que é fiel, que visa o lucro, trabalhador, o corpo padrão. Essa docilidade que até então é ausente nos corpos da população de rua de Alagoinhas, sendo um corpo que não é utilizável, não trabalha e não dá lucro.

Precisamos ressaltar que essa indocilidade é causada pela inviabilidade que manifesta-se por duas características, cor e situação social. Não é nosso objetivo colocar essas pessoas em um muro de vitimismo, mas compreender que há sim um processo de exclusão dualista, pela sua cor e pelo seu estado atual, de estar na rua, dando-lhes a garantia de estereótipos ainda mais humilhantes. É preciso tirar as máscaras que encobrem as desigualdades e esse mito de democracia racial. Para isso é preciso fazer,

A expressão da alteridade e soltar a voz encarcerada, e por isso toca assuntos polêmicos e tabus: falar do não dito, pela perspectiva de quem nunca pôde dizer. Além do mais, a experiência humana guarda em suas minúcias cotidianas - os muros, a dor, a alegria, as perdas... nuances ou clarões do sublime. (FIGUEREDO, 2009, p. 43)

É preciso que se fale desses corpos, sofridos, colocando-os em um lugar de fala que não é meu nem do leitor, mas deles, desses corpos que não obedecem aos padrões sociais hegemônicos e excluídos do mundo. Dentro dessa experiência na cidade de Alagoinhas-Ba, observa-se que esses corpos são automaticamente apagados. Vê-los é uma questão de sensibilidade humana pouco encontrada nas relações sociais. E isso é visivelmente citado por eles.
João ${ }^{2}$ nos diz: Muitas vezes olhado, olhado como nada na rua, né, discriminado como muitas pessoas...o cara é visto como nada muitas vezes." (SIC).

Pedro: Rapaz, foi definir mesmo da população mesmo é bastante pesado, por que o seguinte, a gente é preto e mora na rua, né?, preto sofre, sacana, somos descriminado, a gente queira ou não queira somos descriminados, até o olhar do ser humano você pressente só não pressente mesmo aquele que não quer constar a real mesmo sabe, a verdade é que a gente vai vivendo, né, alguém fala, alguém conspira alguém fala alguma coisa outro diz outra (SIC).

Davi: há, na verdade tem muitas pessoas aí que se orgulha demais vê a gente assim como Pedro disse, preto e morador de rua, que ... passa aqui por longe quer ser melhor do que a gente, tá entendendo?... na rua assim, não é fácil, não. Fica na rua quem tem muita coragem, pra quem está disposto a tudo, me xingam e tudo, já me bateram, eu já bati também aqui em Alagoinhas, já me xingou, eu já xinguei também tudo, aí cada um vai levando a vida (SIC).

É possível perceber então, nas falas supracitadas essa exclusão, e como essa também é sentida por eles, o processo do racismo que leva esse sujeito ao apagamento e a indocilidade de um corpo que por não obedecer aos padrões exigidos é por ora invisibilizado, esquecido não só pelas pessoas mas pelo Estado que maltrata. São exatamente esses comportamentos, de discriminação, desvios, olhares atravessados e medo que dão origem a invisibilidade sofrida por essas pessoas, o que se tem são estereótipos formados acerca dos mesmos, por estarem em situação de rua e com algumas limitações como falta de emprego, moradia, por utilizarem substâncias psicoativas, dentre outros, acabam

${ }^{2}$ Nome fictício, todos os nomes das pessoas citadas no texto com relatos são fictícios, mantendo a integridade e o sigilo necessário. 
tornando-se um perigo para alguns e insignificantes para outros, reforçando ainda mais o pré-conceito.

Para obter essas informações foram perguntados como eles se sentiam morando na rua e se eles se reconheciam como pretos e negros, eles afirmaram que tinham essa noção e então foram obtidas as respostas que serviram como um norte para este trabalho. O próprio Pedro diz, "a gente é preto e mora na rua, preto sofre, sacana". Pessoas em situação de rua é a todo momento controlado pelo sistema que oprime, um sistema hipócrita, que racionaliza seu discurso em desfavor dessa população the colocando sempre num papel de marginal, violentados dia a dia por transeuntes com simples gestos de desprezo ou medo, nesse entre-lugar $^{3}$ vivido por eles, como nos afirma Silva (2010, p. 82).

Dizer "o que somos" significa também dizer "o que não somos". A identidade e a diferença se traduzem, assim, em declarações sobre quem pertence e sobre quem não pertence, sobre quem está incluído e quem está excluído. Afirmar a identidade significa demarcar fronteiras, significa fazer distinções entre o que fica dentro e o que fica fora. A identidade está sempre ligada a uma forte separação entre "nós" e "eles". Essa demarcação de fronteira, essa separação e distinção, supõem e, ao mesmo tempo, afirmam e reafirmam relações de poder.

Essa demarcação e separação entre "eu" e "eles" trazido pela autora corrobora com a ideia de um sujeito que está sempre distante da "socieda-

${ }^{3}$ o "entre-lugar" parte de uma teoria de Silviano Santiago na sua obra Uma literatura nos trópicos, no capítulo "o entre lugar do discurso latino americano" onde destaca-se o lugar do homem contemporâneo nesse lugar movediço, que descoloca-se constantemente, não tendo ele um lugar fixo, sendo manipulado sempre por um sistema que gere os discursos. de", o sujeito negro e periférico sofre com isso cotidianamente, por isso é importante falar sobre essas identidades dessas pessoas que vivem nas ruas e negras, duas situações que agravam ainda mais a situação, o social e a etnia. "O retrato do indivíduo é complexo: espera-se, do ser negro, ou a rebeldia, ou a total subserviência o bom crioulo, a inépcia, a ausência de talentos, a vida sem futuro" (FIGUEREDO, 2009, p. 48).

É relevante destacar que quando o sujeito fala, não fala a partir de um discurso solitário, individual, mas de um grupo de vozes que ressoam com a sua, sendo analisado dessa maneira, um discurso que é grupal, identitário e comum a eles, pretos e subalternos. Nesse sentido a linguagem se apresenta como prática importante através das narrativas/histórias de vida cotidianas, que relatam aquilo que se passa nas ruas e nos seus ambientes e é através da linguagem também que se revelam as identidades, as maneiras de viver e estar na rua que configuram a todo momento uma reelaboração desses sujeitos.

Essas pessoas estão a todo momento se (Re)elaborando em diversas ocasiões da sua vida, seja na arte de fazer de locais públicos um ambiente parecido a um lar, a utilizar objetos e reinventar, como uma geladeira que virou guarda roupas a suas músicas e poesias, o reinventar que nos diz sobre suas estratégias que podem se configurar como um processo de resistência para viver nessa situação e é o que no momento nos interessa (LIMA, 2015).

A partir do pouco que foi falado, podemos dizer que, as duas questões, ser negro e viver na rua torna esse sujeito mais vulneráveis as práticas de racismo. O negro ainda tem que ser visto de maneira depreciativa para a sociedade, sendo uma violência "invi- sível" por tratar-se de uma questão simbólica.

Por não terem o tempo medido e pago, por serem "impuros" e apresentarem defeitos, terem um tempo sem qualidade e não ter seu corpo aplicado ao exercício, essas pessoas tornam-se sujeitos fragilizados na sociedade do poder. Para Foucault (2004, p.11) "o corpo docilizado deve estar no bom emprego do corpo, que permite um bom emprego do tempo, nada deve ficar ocioso, ou inútil: tudo deve ser chamado a formar suporte do ato requerido". Isso foge totalmente dos padrões em que vivem as pessoas de rua, vivendo em um tempo ocioso, em uma "liberdade" que foi imposta pela sociedade capitalista que os segregou, fora de uma regulamentação imposta pelo poder e pela lei da construção disciplinar que nos rege. Não fazem parte dessa organização disciplinar que compõe forças, em que a disciplina deixou de ser a repartição de corpos passando a ser acúmulos de forças para ser um aparelho eficiente que o capitalismo necessita. A aparência da indocilidade, os corpos que não geram lucros, seria um crime, pois o objetivo é construir corpos que forcem e organizem, produzam e sejam produtos de forças calculadas que levem a prática disciplinar (Idem)

Para isso é preciso compreender que discurso e poder são indissociáveis, ambos andam na mesma esfera, oferecendo sempre os "dois lados da moeda". Há sempre perigo em qualquer discurso, em qualquer ambiente em que exista o poder, mas é um risco que vale a pena para visibilizar o que por muito tempo foi invisibilizado e silenciado. É poder criar estratégias, olhar fissuras e tratá-las, pensando metaforicamente, em um sentido que caminha em benefício ao conjunto, não a apenas um grupo social isolado. 
Trata-se de compreender as linguagens como um campo e dispositivo sóciocultural de experiências desses sujeitos que parece representar uma possibilidade de luta no mundo contemporâneo.

\section{As letras e a arte como processo de resistência na rua}

É imprescindível pensar no esquecimento e apagamento em que essas pessoas sofrem constantemente, como já salientado neste trabalho. Por isso, dentro desta pesquisa, que é um "desmembrar" da minha Dissertação de Mestrado, tento mostrar as maneiras de existir e resistir nas ruas, através das letras, que versam em textos, músicas (do gênero Hip-Hop), poesias, assim como pinturas, que serão abordadas no decorrer das nossas discussões, fazendo uma estreita ligação entre essas práticas, viabilizando um outro olhar sobre esse público.

Por isso é tão importante a mediação das relações sociais com a sua obra de arte e assim entender que existe ali, potencialidades artísticas que são extremamente importantes para esses sujeitos, que neste caso, se dá num ambiente complexo, onde as tramas das vida se passam nas ruas, debaixo da árvore e marquises. As funções estéticas aqui pouco importam para mim e para os autores ao qual faço menção, o que desejamos é falar de uma arte, por exemplo, que falam das suas tramas, dos seus processos invisibilizatórios, que acarreta um novo fazer que por meio da arte é possível analisar, como diz o próprio Vygotsky (2004), analisar a arte como técnica social do sentimento que envolve sua vida e suas histórias, que se exprimem num fazer artístico.

"Em baixo da Árvore ,
A verdade é nua e crua,

A vida cheia de altos e baixos

Porém é preciso saber viver

Tem coisas na vida que é passageira

Mas tem que saber a vida viver" (Antônio, morador de rua da cidade de Alagoinhas.)

É possível perceber através do poema de seu Antônio os processos de resistências ao viver na rua como um processo endurecedor, "a verdade nua e crua", sendo como nos afirma Santiago (2010) uma produção de uma sociedade hierárquica e ocidental que ausenta essas pessoas do seu processo de construção social, exilando-os, deixando-os fora de vários processos oportunos como emprego, educação, por exemplo. Assim, a literatura apresenta-se como uma possível expressão daquilo que está reprimido, como uma escrita de si, que versa sobre ela.

Segundo Klinger (2006) a escrita de si trata-se de narrativas autobiográficas ou biográficas nas quais os sujeitos recontam suas histórias. a autora nos diz que a escrita de si é um sintoma da época atual, e o fato de ser um sintoma atual, decidimos utilizá-lo como instrumento de pesquisa que mais se aproxima do nosso objetivo que é analisar e compreender essas "vozes", afinal o que existe é um sistema que favorece esse novo método que nos situa nesses discursos.

A escrita de si não representa somente uma pessoa, mas toda uma comunidade que se faz presente em sua narrativa. A escrita de si não se apresenta sob marca da memória da classe, mas aparece como indagação de um eu que, à princípio parece ligado ao narcisismo midiático contemporâneo. A própria vida está imersa numa trama de relações sociais e todo relato autobiográfico remete para além de si mesmo, porque não se pode pensar em um eu fora da sua caixa, tudo está interligado com o ambiente no qual vive a comunidade (Klinger, 2006)

Estar na rua e ser negro são questões que esses sujeitos - homens, mulheres - vivenciam cotidianamente. A falta de oportunidade leva esses indivíduos a mal remuneração ou nenhuma remuneração, tendo uma ligação forte também com sua cor como nos afirma Figueredo (2009, p. 52).

A escravidão antes trabalho
forçado e sem remuneração,
toma outro conceito: trabalho
muito mal remunerado e carga
horária acima da remuneração.
A exploração mudou de nome:
de escravidão, para trabalho
mal remunerado. As mulheres
(negras e não-negras) e os ho-
mens negros ainda são os mais
prejudicados.

Dessa forma, coadunando com a autora citada, podemos também dizer que o jogo só mudou de nome: as senzalas foram substituídas pelas periferias e casebres. Há segregação entre os que tem e os que não têm, resultando em um índice de desemprego gritante entre os negros, além da sua maioria ter baixa escolaridade ou o salário abaixo do mínimo.

Por viverem em um ambiente onde a relação de poder opera no ceio dela, as vozes desses sujeitos são silenciadas, e como aponta Foucault (2004), na sua obra. "A Ordem do discurso", todo discurso é controlado, organizado, manipulado por quem detém o poder, construindo cadeias de ordens que impedem essas pessoas em situação de rua de se expressar, por não existir valorização do que "produzem" e do que se é enquanto seres em estágio marginalizado e fragilizado. Assim, a escrita de si apresenta-se nesse trabalho de maneira impetuosa, fruto de um silenciamento de "vozes" e corpos que não são ouvidos e enxergados por sua condição subalterna, 
visto que esses sujeitos se percebem frente aos outros visualmente de maneira impotente, submissa.

A escrita de si, as histórias de vida, nesse ambiente, apresentam-se como uma estratégia de $(\mathrm{Re})$ significação dessa pessoa, "a autobiografia, é desafiadora, provocativa, há nela muitos mistérios, o escritor ao escrever sua vida, engendra a si próprio" (SOUZA, 2011, p. 03). A história de vida permite e instaura o livre trânsito entre passado e futuro, como nos afirma a referida autora.

Aqui na rua, podemos ser reconhecido como nada, Mas temos consciência ninguém é melhor que ninguém e a humildade prevalece.

Refrão: Acima de mim, só Deus e a baixo só o chão $2 \mathrm{X}$

E se um dia a luz da nossa amizade apagar, foda-se. A gente acende uma vela

E aprenda meu irmão Não viva que sua presença seja notada mas sim sua falta seja sentida e lembre meu irmão Acima de mim, só Deus e a baixo só o chão $2 \mathrm{X}$ Autor: (Re) existência

(Re) existência, por exemplo, relata na sua letra as dificuldades de viver nesse ambiente hostil. Ele é um jovem de 18 anos que teve a infância ceifada por uso de substâncias psicoativas, prática muito comum entre jovens, negros e de baixa renda. Hoje (Re)existência escreve seus hip-hops e pinta, sendo a pintura "meu divertimento, aí fico aqui imaginando as coisas, ai faço isso, sabe?" (SIC). Essa é a maneira de (Re)existência resistir na rua.
Nesse meio tempo, surgiram oportunidades de encaixá-los em algumas oficinas que acontecem no Centro de Cultura da Cidade de Alagoinhas, mas todas elas foram negadas, chegando a ouvir de um professor /pesquisador do curso de pós graduação , que coordenada uma oficina de Hip-Hop a seguinte pergunta: "como iremos encaixar uma pessoa que não tem a mínima condição de sobrevivência no grupo? Não tem nem Whatsapp." É possível perceber como as injustiças sociais atingem diretamente essas pessoas. No mundo capitalista $o$ "ter" é objeto de desejo para o outro. Se não tem, não me interessa, pregando a falsa democracia de "o mundo para todos". Assim Figueredo (2009, p. 50) nos afirma que "toda violência simbólica fere a moral, desta forma, todas as violências desembocam na violência Moral".

Como já exposto (Re) existência desenha muito bem. Segundo ele, é o que ele sabe fazer de melhor, aprendeu na escola, disse que não fazia nada na escola, só desenhava, seu caderno só tinha desenhos, nessa ida ao encontro do grupo pedi para que ele fizesse um desenho e ele fez, um samurai, um desenho mitológico, curioso perguntei: porque esse desenho? Ele me indagou:

"você trabalha na área de psicologia que já até deu para perceber, porque a gente já vê logo. Sabe por que? Porque se fosse para trabalhar para psicólogo, eu conheço quando é psicólogo, porque já vai entrando na mente da pessoa, antes de você falar já vai entrando no seu psicológico, mas você trabalha com cultura, né, mas samurai representa força, Ariel, e para viver como a gente vive sabe vei a gente tem que ter força, primeiramente em Deus, depois na gente e é isso, por isso eu fiz um samurai, pode levar, eu fiz para você, sacana". (SIC).
O Samurai ${ }^{4}$ como falado por ele representa essa força que é preciso ter para viver na rua, logo de início da narrativa, ele fica com medo, achando que eu iria "entrar" na mente dele, depois de mais um longo papo, me disse que, onde ele ficou preso havia uma psicóloga em que ele era atendido, que mexia muito com ele.

"A obra de arte emerge na fratura entre a terra e o mundo, ou entre o que prefiro traduzir como a ausência de sentido na materialidade do corpo e da natureza e a doação de sentido na história e no social" (JAMERSON, 2007 p. 05), quando ele desenha, ou escreve seus poemas, Hip-Hop, é exatamente nesse sentido, quando (Re) existência diz que o samurai representa força e que para esta ali é preciso ter força, ele traz essas características de alguém que esta deslocado, da ausência dessa força que Jameson chama de ausência do sentido da materialidade.

Como nos fala Foucault (2004), essa arte, aqui projetada, trata-se de um movimento diferente, "trata-se, não de falar do indizível, não de revelar o que está oculto, mas, pelo contrário, de captar o já dito; reunir aquilo que se pôde ouvir ou ler, e isto com uma finalidade que não é nada menos que a constituição de si." (FOUCAULT, 2004 p. 03)

A arte e vida nos leva a perceber novas formas que aparecem com estilos e maneiras diferentes, fotos, artesanatos, pinturas, podendo fazer um comparativo entre o heróico e o cotidiano, na vida dos sujeitos de rua, se misturando de forma inigualável, num fabulismo de vida trazido por (ARFUCH, 2010, p. 71)." como uma ordem, como um devir de experiência, apoiada na garantia de uma existência real." Que fala sobre a experiencias

${ }^{4}$ Figura 1, colocada em anexos apresentada no final do texto. 
dessas pessoas, dando um sentido maior a sua vida, uma voz que que conta e outorga sentindo a história pessoal, que fala sobre amor, dos desprezos, das dores, trata-se de uma voz enunciativa que precisa ser ouvida, prestada atenção, valorizada e que muitas vezes se traduz na arte da poesia, da pintura, da música. A arte que se faz vida.

E reexistir por entre as brechas das armaduras que constroem os binarismos de morte como sistemas e estruturas que deveriam ser fixas, sem possibilidade de reinscrição de si no muro invisível e ao mesmo tempo tangível do que nos torna humanos (SOUZA; JOVINA; MUNIZ, 2018, p.03)

Como nos diz a referida autora, é preciso criar armaduras para existir em alguns espaços, como na rua, um corpo negro, pobre e marginalizado. É possível perceber como essa figura do samurai, representa para ( $\mathrm{Re}$ ) existência a força para lidar com o cotidiano da rua, em um movimento de extrema fragilidade e resistência, de uma violência que afeta o psicológico por sentir-se fora de um meio, por sentir-se só. Pessoas em situação de rua e pessoas negras, neste caso, a população/grupo ao qual me refiro, vivem constantemente esse apagamento, sendo também sempre julgadas. Considerar a arte a narrativa dessas pessoas é mostrar à nossa sociedade preconceituosa em diversos aspectos, que essas pessoas têm suas potencialidades, e que elas também tem suas histórias de dor e de alegria, levando esse público a uma tentativa de compressão desses indivíduos.

\section{CONSIDERAÇÕES FINAIS}

Falar de relação étnicos raciais é adentrar em um universo importante, mas angustiante, esse local, que tam- bém é meu, deste corpo que sente e sabe o que é pobreza e racismo. Os subalternos apresentados e conceituados no presente trabalho vem sofrendo cotidianamente com os ataques dos que detém o poder, sendo este um ambiente de debates acadêmicos oportuno para o atual momento político. “É importante ressaltar que falar de preconceito e exclusão não é implantar um muro de lamentações e revolta, e sim "derrubar" o muro da democracia racial, tirar a máscara e o véu que encobrem as desigualdades explícitas no cenário nacional (FIGUEREDO, 2009,p.43).

Sabe-se que esses corpos que este trabalho apresenta são esquecidos, fruto de uma longa história que oprimiu e segregou estas pessoas, deixando-lhes em um lugar de inutilidade. Os dados segundo o censo demográfico do IBGE de 2017, nos revela que, de cada 100 jovens assassinados, 71 são negros, do sexo masculino e periféricos, pobres. O que percebemos e que esses jovens continuam sendo assassinados como se vivessem numa guerra.

Um dos pontos mais importantes desse trabalho, é tornar visível uma concepção antagônica sobre o que pensam as pessoas acerca das pessoas em situação de rua, trazendo sim, seus enfrentamentos, dores, mas mostrando suas potencialidades como visto no corpo deste trabalho, que desmembra de uma dissertação. É preciso ressaltar que a temática "pessoas em situação de rua" ainda vem sendo pouco discutida no mundo acadêmico, o que nos impulsionam ainda mais para a discussão através de um novo olhar que não foge do cuidado, mas que potencializa sua existência a partir de uma perspectiva mais amplo e singular, que é pensar a arte nesse contexto. Com isso, também levamos esse sujeito a pensar seu próprio posicionamento social enquanto cidadão, além da disseminação de uma nova ordem sobre esse público, através da sua produção.

É possível perceber com os relatos trazidos que esses corpos são apagados, esse apagamento que é fruto de uma geração que sempre segregou e sempre valorizou somente o corpo que produz. As pessoas em situação de rua além de fazer parte de classe subalterna não produz e não tem recursos seja de ordem financeira ou emocional como uma educação não formal que favorecesse a sua visibilidade como sujeitos com possibilidades de produzir, pois são desacreditados pelo Estado. Pela inexistência de recursos como supracitadas, esses sujeitos tornam-se (in)dóceis. Essa desproporção de riqueza dá vazão a novas vazões de pobreza que se estabelecem nas grandes cidades. Esse movimento de aumento de pobreza quando as produções industriais estão crescendo torna-se antagônico e por consequência excludente.

Sua maneira de existir, na rua, sem dinheiro, trabalho, fazem com que criem capacidades compensatórias de viver num ambiente "impróprio" tornando-os resistentes. Vivendo com dificuldades de comer, beber, vestir, dentre outras coisas, tem os direitos humanos sempre ceifados por sua condição.

Contar suas histórias permite a essas pessoas que elas expressem seus sentimentos, suas dores, suas angústias, frutos de uma trajetória de vida sofrida, que se expressa nas narrativas, nas artes como pinturas e Hip-Hop, que configura-se como um ato de reconstrução ao perceber na sua própria narrativa e arte, como sinônimos de resistências que se (re)significa neste trabalho, A pesquisa, configura-se como uma possibilidade de redirecionamento para as potencialidades das 
pessoas em situação de rua da cidade de Alagoinhas, reafirmando suas existências e fazendo um movimento inverso ao qual as pessoas estão acostumadas a fazer, diferenciando-as do estigma socialmente construído possibilitando melhoras socias ao que podemos chamar de direitos humanos

Para Vigotski (1999), a arte está sempre em total relação com a vida, com a realidade e que essa compreensão é que nos permite enxergar as potencialidades humanas, que para ele está ligado a capacidade de resolver problemas, de transformar as coisas. Pensando nessa perspectiva podemos dizer que a arte estar em total ligação com a vida, com as relações sociais, é importante afirmar que a arte nunca será uma cópia fiel da sua realidade objetiva, mas tem a capacidade de falar sobre ela, podendo assim construir um novo sentido para suas histórias através dos seus corpos, narrativas e artes que cotidianamente são marginalizados e estereotipados.

\section{REFERÊNCIAS}

ARFUCH, Leonor. O espaço Biográfico: Dilemas da subjetividades contemporânea. EDURJ, 2010.

AGUIAR.J; BASTOS.N. Arte como conceito e como imagem :A redefinição da "arte pela arte". Revista Social, USP, SP,v. 25, n. 2 Novembro, 2013.

COSTA, João. Histórias de vida de pessoas em situação de rua da cidade de Natal|RN: Fotografias do trabalho em construção identitária individual. 2016. 280.f.tese (doutorado em Linguística aplicada) Centro de Ciências Humanas, letras e artes, Universidade Federal do Rio Grande do Norte. NATALIRN.

CERQUEIRA, Daniel et al, Altas da violência 2017. IPEA. Rio de Janeiro, Junho de 2017.
FOUCAULT, Michel. A ordem do discurso. São Paulo: Ed 24. Edições Loyola, 2004.

FOUCAULT, Michel. Os corpos dóceis. In: Vigiar e Punir: nascimento da prisão. tradução de Raquel Ramalhete Petrópolis, Vozes, 1987

FIGUEREDO, Fernanda. A mulher negra dos cadernos negros: Autoria e representação. (Dissertação) F.128. Programa de pós graduação Estudos Literários, Belo Horizonte, 2009.

JAMESON, Fredric. Pós-Modernismo: a lógica cultural do capitalismo tardio. 2.ed. São Paulo: Ática, 2007.

SANTIAGO, Ana. Literatura de autoria feminina negra: (des)silenciamentos e ressignificações. Fólio- revista de letras, Vitória da conquista. V.2,n. p.20-37.

Jan./jun.2010.

SANTIAGO, Silviano. Democratização no Brasil: 1979-1981 (Cultura versus Arte) In, Declínio da Arte e Ascensão da Cultura. Florianópolis: ABRALIClLetras contemporâneas, 1998. p.11-23

SANTOS.O. M. A luta desarmada dos subalternos. Belo Horizonte. EdUFMG. 2016.

SILVA, Ana. Literatura de autoria negra feminina: (des) silenciamentos e ressignificações. Ed. Fólio. Vitória da Conquista. V2. N1 Jan\Jun. 2010.

SOUZA, Ana; JOVINA, I; MUNIZ,K. Letramento de reexistência: um conceito em movimento negros. Ed. Especial. V 10. Janeiro de 2018.

LIMA, Mota. Relações étnico-raciais na escola: o papel das linguagens. 1a edição. Salvador: ED.UNEB, 2015.

OLIVEIRA. Fátima. Ser negro no Brasil: alcances e limites. Estud. av. vol.18 no.50São Paulo Jan./Abril.2004

VIGOTSKI, L. S. (1999). Psicologia da Arte. São Paulo: Martins Fontes.
KLINGER, Diana. Escritas de si, escritas do outro: autoficção e etnografia na narrativa latino-americana contemporânea. 2006. 206 f. Tese (doutorado em Letras) Instituto de letras, Universidade do Rio de Janeiro, RJ.

\section{ANEXOS}

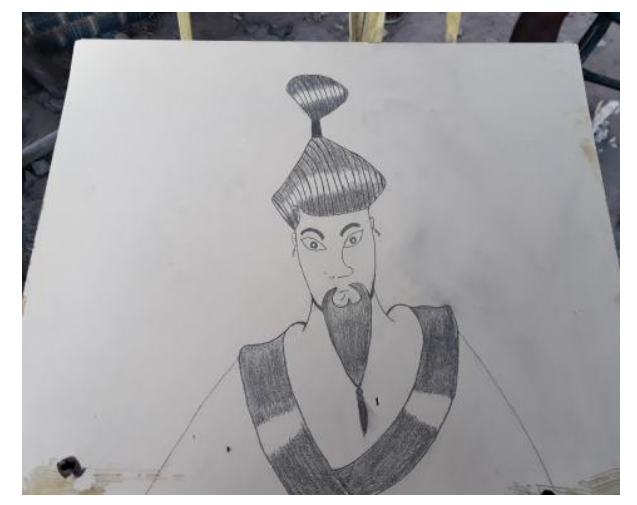

